일반논문-09-14-6-03

$$
\begin{gathered}
\text { 방송 콘텐츠의 후반 제작을 위한 카메라 추적 시스템 } \\
\text { 오 주 현(a,b), 남 승 진a), 전 성 } \left.\text { 규 }^{\mathrm{a})} \text {, 손 광 훈 }\right)^{\ddagger}
\end{gathered}
$$

\title{
A Camera Tracking System for Post Production of TV Contents
}

\author{
Juhyun $\mathrm{Oh}^{\mathrm{a}, \mathrm{b})}$, Seungjin Nam ${ }^{\text {a) }}$, Seong-gyu Jeon ${ }^{\mathrm{a})}$, and Kwanghoon Sohn ${ }^{\text {b) }}$ \\ 요 약
}

과거 값비싼 워크스테이션에서만 구현 가능했던 실시간 가상스튜디오를 이제는 하드웨어의 발달로 개인용 컴퓨터에서도 운용할 수 있게 되었다. 그럼에도 불구하고 여전히 실시간 제작의 그래픽 품질에는 한계가 있기 때문에 영화나 드라마에서는 후반 제작 (post production)으로 그래픽을 합성하는 것이 일반적이다. 그러나 후반 제작을 위한 순수 영상 기반 카메라 추적은 많은 작업 시간 을 요하며, 자주 불안정한 결과를 보인다. 이를 극복하기 위해 가상스튜디오와 마찬가지로 촬영 단계에서 카메라 모션 데이터를 센 서로부터 수신하되, 이를 저장하여 후반제작에서 활용할 수 있는 시스템(POVIS: post virtual imaging system)을 제안하였다. 실사와 그래픽의 매끄러운 정합을 위해서는 정확한 카메라 캘리브레이션이 선행되어야 하는데, 이를 위해 두 장의 평면 패턴만을 이용하여 간단하게 수행할 수 있는 캘리브레이션 방법을 사용하였다. 또한 카메라 센서 데이터는 기계적 부정합 등으로 인해 약간의 오류를 포함하게 되는데, Kalman 필터를 이용하여 이를 줄이는 방법을 제안하였다. 개발된 POVIS는 다큐멘터리 제작에 사용되어 작업 시 간을 크게 단축시키고, 특징점의 부재로 인해 기존의 방법을 적용할 수 없는 영상에서의 카메라 추적을 성공적으로 수행하였다.

\begin{abstract}
Real-time virtual studios which could run only on expensive workstations are now available for personal computers thanks to the recent development of graphics hardware. Nevertheless, graphics are rendered off-line in the post production stage in film or TV drama productions, because the graphics' quality is still restricted by the real-time hardware. Software-based camera tracking methods taking only the source video into account take much computation time, and often shows unstable results. To overcome this restriction, we propose a system that stores camera motion data from sensors at shooting time as common virtual studios and uses them in the post production stage, named as POVIS(post virtual imaging system). For seamless registration of graphics onto the camera video, precise zoom lens calibration must precede the post production. A practical method using only two planar patterns is used in this work. We present a method to reduce the camera sensor's error due to the mechanical mismatch, using the Kalman filter. POVIS was successfully used to track the camera in a documentary production and saved much of the processing time, while conventional methods failed due to lack of features to track.
\end{abstract}

Keyword : POVIS, camera tracking, lens calibration, Kalman filter

a) 한국방송 방송기술연구소

Broadcast Technical Research Institute, KBS

b) 연세대학교 전기전자공학과

School of Electrical and Electronic Engineering, Yonsei University

\# 교신저자 : 손광훈 (khsohn@yonsei.ac.kr)

- 접수일(2009년7월22일),수정일(1차:2009년9월25일,2차:10월5일,3차:10월20일), 게재확정일(2009년11월2일)

\section{I. 서 론}

과거 대규모 예산을 투입한 블록버스터 영화 제작 위주 로 사용되던 컴퓨터 그래픽스(computer graphics, CG) 기술 이 점차 보편화되면서 $\mathrm{TV}$ 드라마, 사극, 다큐멘터리 등의 
제작에서도 일반적으로 쓰이게 되었다. 이러한 $\mathrm{CG}$ 작업의 대부분은 실사와 그래픽 영상의 합성이며, 그래픽 영상을 생성하기 위해서는 실사 영상 촬영 시 사용된 카메라 모션 데이터가 필요하다. 이와 같은 그래픽 합성 작업은 크게 실 시간 제작(live production)과 후반 제작(post production)의 두 가지 범주로 나눌 수 있다. 가상 스튜디오 ${ }^{[1]}$ 나 가상 이 미징 ${ }^{[2]}$ 시스템과 같은 실시간 제작에서는 카메라에 부착 된 센서를 이용하여 카메라를 실시간으로 추적하여 그래 픽 렌더링 시스템에 반영한다. 실시간 카메라 추적 시스템 은 하드웨어 센서 장치가 필요한 대신, 실시간으로 정확한 추적이 가능하다는 장점이 있다. 이에 반해 후반 제작에서 는 별도의 하드웨어 장치 없이 촬영한 후 영상만을 분석하 여 카메라를 추적하며, 이러한 목적의 상용 소프트웨어에 는 Boujou ${ }^{[3]}$ 와 $\mathrm{PFTrack}^{[4]}$ 등이 있다. 그림 1에 두 가지 추적 방식의 예를 제시하였다.

두 가지 제작 방식 중 소프트웨어 기반 후반 제작은 촬영 된 영상만을 분석하여 카메라 모션의 복원이 가능하다는 장점이 있다. 그러나 촬영할 장면에 정적(static)이면서 추 적이 가능한 특징점들(feature points)이 충분히 존재해야 한다는 제약이 있고, 매우 많은 계산 시간이 걸리며, 알고리 듬의 한계로 인해 추적에 실패하는 경우가 많다는 단점이
있다.

그에 비해 실시간 카메라 추적은 촬영될 장면에 따른 제 약 없이 강인한 추적 결과를 얻을 수 있으나 그 응용은 가상 스튜디오와 같은 실시간 제작에만 한정되어 있었다. 본 연 구는 하드웨어 센서를 이용한 실시간 카메라 추적을 후반 제작에도 적용하기 위한 것으로서, 안정되고 정확한 카메 라 추적 성능과 후반 제작에 의한 높은 그래픽 품질을 동시 에 얻을 수 있게 한다. 그림 2는 POVIS의 전체 시스템 구성 도와 데이터의 흐름을 보여준다.

그림 2에서 카메라에 부착된 줌(zoom), 포커스(focus), 팬(pan, 좌우 회전), 틸트(tilt, 상하 회전) 센서 데이터는 센 서박스를 거쳐 운용PC의 POVIS 소프트웨어에 의해 저장 된다. POVIS 소프트웨어는 녹화기(VCR)를 원격 제어하여 녹화를 시작하며, 녹화되는 영상과 센서데이터를 동기화하 기 위해 VCR로부터 SMPTE 타임코드 ${ }^{[5]}$ 를 수신하여 센서 데이터와 함께 저장한다. 저장된 미 가공 센서 데이터는 렌 즈 캘리브레이션 데이터를 참조하여 의미 있는 카메라 데 이터로 변환된다. 기계적 오류로 카메라 데이터에 떨림 (jitters)이 존재하는 경우에는 보정 과정을 거친다. 이와 같 이 추적된 카메라 데이터를 Maya 등의 그래픽 소프트웨어 에 불러들여서 렌더링한 그래픽을 $\mathrm{PC}$ 에 저장된 비디오에
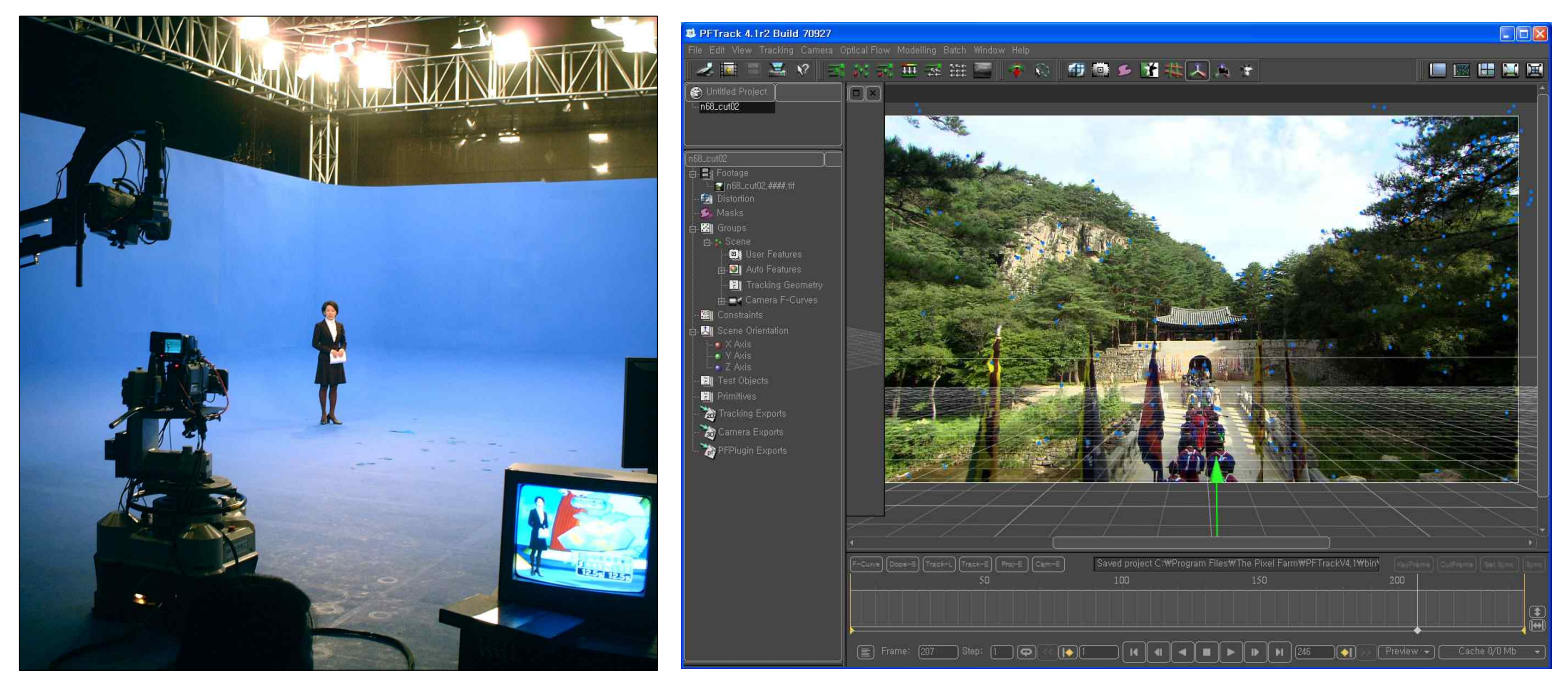

그림 1. 실시간(왼쪽)과 오프라인(오른쪽) 카메라 추적 솔루션

Fig. 1. Camera tracking solutions, real-time(left) and offline(right) 


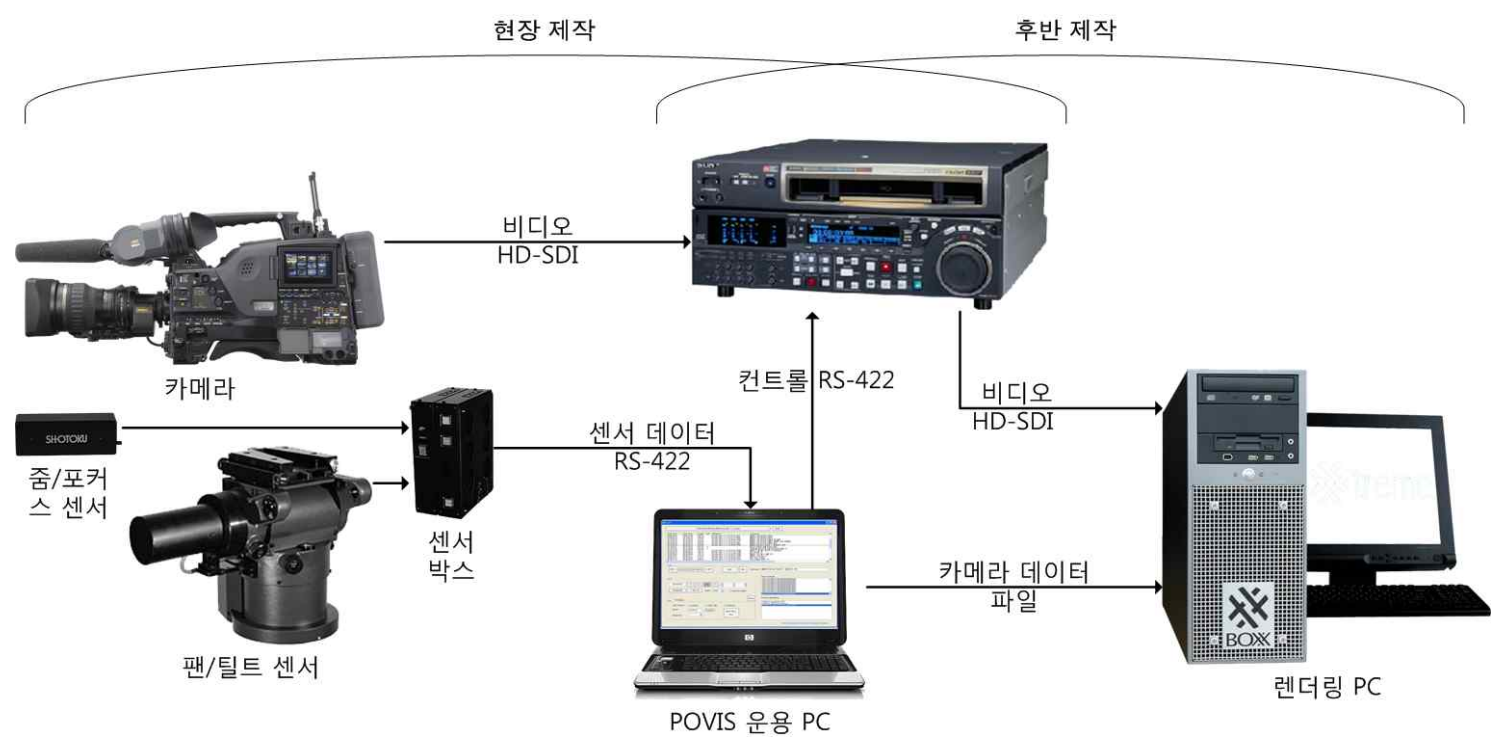

그림 2. POVIS 시스템 구성도와 데이터 흐름

Fig. 2. POVIS block diagram and data flow

합성함으로써 후반 제작이 완료된다.

본 논문은 다음과 같이 구성된다. 2장에서는 정확한 카메 라 추적을 위해 선행되어야 하는 줌렌즈 캘리브레이션 방 법을 소개한다. 3 장에서는 센서의 기계적 오류를 보정하는 방법을 제안하고, 4장에서는 카메라 추적 결과를 그래픽 렌 더링에 적용하기 위한 플러그인과 렌즈 왜곡 처리 방법을 소개한다. 5장에서는 제안된 시스템을 이용한 실험 결과를 보이고, 6장에서 결론을 맺는다.

\section{II. 줌렌즈 캘리브레이션}

카메라에 부착된 렌즈센서와 회전센서는 각각 줌, 포커 스 값과 팬, 틸트 값을 실시간으로 알려준다. 회전센서 값은 그 자체로 의미 있는 수치로서, 주어진 해상도(degree/motor unit)를 가지고 $0 \sim 360$ 도의 팬과 틸트 각도로 치환하여 바로 사용할 수 있다. 그러나 렌즈센서에서 알려주는 줌과 포커스 모터의 회전 값은 그 자체로는 그래픽 이미지를 생 성하기 위한 가상 카메라에 적용할 수 없으며, 그 값에 해당 하는 초점거리(focal length), 프로젝션 중심(projection center)의 위치, 방사 왜곡 계수(radial distortion coefficients)
등의 파라미터로 변환해야 의미를 가진다. 이처럼 렌즈센서 값을 의미 있는 수치로 변환하기 위한 룩업 테이블(look-up table)을 생성하는 작업이 줌렌즈 캘리브레이션이라 할 수 있다. 줌렌즈 캘리브레이션은 본 논문에서 제안된 후반 제작 을 위한 시스템 뿐 아니라 일반 가상스튜디오 제작에서도 필수적으로 요구되는 작업이며, 대다수의 제작 현장에서 많 은 작업 시간을 들여 수동으로 수행하고 있다. 본 연구에서 는 복잡한 하드웨어나 3차원 캘리브레이션 오브젝트를 사용 하거나 여러 번 패턴을 이동하지 않고도 ${ }^{[6,7]}$, 빠른 시간 내에 정확한 캘리브레이션을 수행하기 위하여 ${ }^{[8]}$ 에서 제안된 방법 을 단순화하여 사용한다. 그림 3은 줌렌즈 캘리브레이션을 위한 카메라와 패턴 모델이다. 회전을 이용한 캘리브레이션 방법이므로, 회전센서가 내장된 팬/틸트 헤드를 사용한다. 한 가지 유의할 사항은 그림 3에 나타난 카메라 모델의 사용 은 렌즈 캘리브레이션에만 국한되며, 5장의 실험결과에서 알 수 있듯이 제안된 POVIS는 크레인 카메라 등 여러 가지 카메라 형태에 사용 가능하다는 점이다.

그림 3 의 카메라 모델에서 알아내야 하는 파라미터들은 줌-포커스 값에 따른 렌즈의 초점거리(f), 카메라 회전축으 로부터의 프로젝션 중심의 거리( $\mathrm{t})$, 그리고 렌즈 왜곡 계수 $\left(\kappa_{1}\right)$ 이다. 이때 설치된 패턴들의 위치와 회전, 즉 포즈 


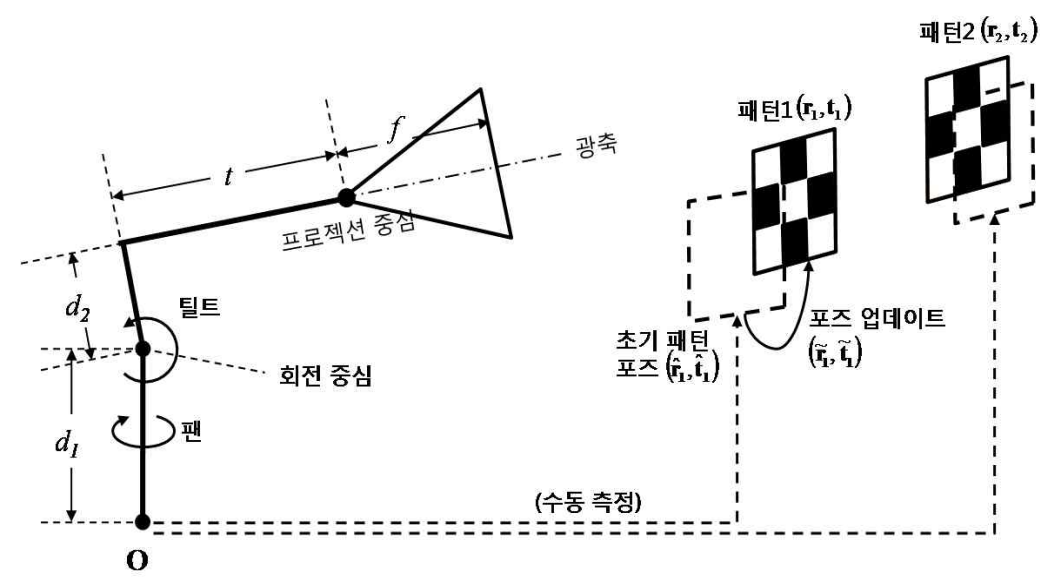

그림 3. 렌즈 캘리브레이션을 위한 카메라와 패턴

Fig. 3. The camera and patterns for lens calibration

(pose)를 정확하게 측정하는 것은 매우 어려운 일이다. 본 논문에서는 전체 $\mathrm{N}$ 개 중 $\mathrm{n}$ 번째 패턴의 포즈를 $\left(\mathrm{r}_{\mathrm{n}}, \mathrm{t}_{\mathrm{n}}\right)$ 라 할 때 줄자 등을 이용해 대략적으로 측정한 초기 포즈 $\left(\hat{\mathrm{r}}_{\mathrm{n}}, \hat{\mathrm{t}}_{\mathrm{n}}\right)$ 와 실제 포즈의 차이 $\left(\tilde{\mathrm{r}}_{\mathrm{n}}, \tilde{\mathrm{t}}_{\mathrm{n}}\right)$ 를 미지수로 간주하여 다른 파라미터들과 함께 추정한다. [8]에서는 모든 줌 영 역에서 패턴의 포즈를 추정하였으나 본 논문에서는 최대 줌-아웃 설정에서만 패턴의 포즈를 추정함으로써 알고리 듬을 단순화하고 수렴성을 높였다. 다음과 같이 재투영 오류(reprojection error)를 최소화하는 파라미터 집합 $\mathrm{p}=\left[f, t, \kappa_{1}, \tilde{\mathrm{r}}_{1}, \tilde{\mathrm{t}}_{1}, \tilde{\mathrm{r}}_{2}, \tilde{\mathrm{t}}_{2}\right]^{\mathrm{T}}$ 를 Levenberg-Marquardt 방법 ${ }^{[9]}$ 으 로 구한다.

$$
\mathrm{p}=\operatorname{argmin} \sum_{n}^{N} \sum_{m}^{M_{n}}\left\|\mathrm{~m}_{\mathrm{nm}}-\widehat{\mathrm{m}}_{n m}\right\|
$$

$\mathrm{n}$ 번째 패턴의 $\mathrm{m}$ 번째 포인트 $\mathrm{M}_{n m}=[X, Y, Z, 1]^{T}$ 는 추정되 는 카메라 파라미터 $\hat{\mathrm{p}}$ 에 의해서 (2)와 같이 $\widehat{\mathrm{m}}_{n m}=[x, y, w]^{T}$ 으로 재투영(reprojection)된다. $d_{1}, d_{2}$ 는 수동으로 측정한 값이다.

$$
\begin{aligned}
& \widehat{\mathrm{m}}_{n m}=L(r) \mathrm{K}[\mathrm{R} \mid \mathrm{t}]\left(\mathrm{M}_{n m}+\mathrm{d}_{1}\right) \\
& \text { 이 때 } \quad \mathrm{t}=\left[0,-d_{1},-t\right]^{T} \\
& \text { 그리고 } \quad \mathrm{d}_{1}=\left[0,-d_{2}, 0\right]^{T}
\end{aligned}
$$

여기에서 $\mathrm{R}$ 은 팬과 틸트 센서값으로부터 얻어지는 회전 행렬이다. 카메라 내부 변수 $\mathrm{K}$ 는 다음과 같이 정의된다.

$$
\mathrm{K}=\left[\begin{array}{ccc}
f & s & c_{x} \\
0 & \text { af } & c_{y} \\
0 & 0 & 1
\end{array}\right]
$$

방송용 레벨의 카메라에서 skew $\mathrm{s}=0$, aspect ratio a $=$ 1 로 가정할 수 있다. 영상에서 주점(principal point)의 위치 $\left(c_{x}, c_{y}\right)$ 는 줌 동작에 의한 집중선이 만나는 점으로 가정하 여 ${ }^{[10]}$ 최소자승법(least squares)으로 구할 수 있다. 렌즈에 는 단순히 선형적으로 모델링할 수 없는 왜곡이 존재하는 데 ${ }^{[11]}$, 왜곡 중심으로부터 (왜곡 없이) projection된 점까지 의 거리(radial distance)를 r이라 할 때 다음의 radial lens distortion 모델 ${ }^{[12]}$ 을 사용한다. 왜곡 중심은 주점과 동일하 다고 가정한다.

$$
L(r)=1+\kappa_{1} r^{2}
$$

식 (1)을 이용하여 카메라 파라미터를 추정할 때, 미지수 보다 많은 개수의 방정식을 제공하기 위하여 줌과 포커스 를 고정한 채 카메라를 팬/틸트함으로써 5 10장의 이미지 를 촬영하여 사용한다. 이는 패턴을 사용하지 않는 회전 기 반 셀프 캘리브레이션 방식[13]과 유사하다. 


\section{III. 센서 데이터 보정}

수많은 기어들의 집합인 카메라 센서는 백래시(backlash) 와 마찰 등 여러 가지 기계적 원인에 의한 오차 가능성을 내포하고 있다. 센서 데이터의 잡음(noise)은 특히 크레인 카메라의 경우 두드러지는데, 긴 크레인 암(crane arm)에 의한 무게와 진동 등이 그 원인인 것으로 보인다. 여기서는 센서 데이터의 잡음을 간단한 Kalman 필터 ${ }^{[14]}$ 를 이용해 효 율적으로 필터링하는 방법을 제안한다. Kalman 필터는 Median 필터 등에 비해 버퍼링 없이 실시간으로 처리가 가 능하다는 장점이 있으며, 카메라 헤드는 뉴턴의 운동법칙 에 의해 그 움직임을 제한하는 것이 매우 타당하다고 할 수 있다. 우선 $\mathrm{k}$ 번 째 timestep에서 실제 카메라의 위치와 속도를 다음과 같이 정의하자.

$$
\mathbf{x}_{\mathrm{k}}=\left[\begin{array}{l}
x \\
\dot{x}
\end{array}\right]
$$

카메라가 $\Delta t$ 동안 zero mean과 표준편차 $\sigma_{a}$ 의 정규분 포를 가지는 가속도 $a_{k}$ 에 의해 가속된다고 하면, 뉴턴의 운 동 법칙에 의해 다음의 식을 얻을 수 있다.

$$
\begin{aligned}
& \mathrm{x}_{\mathrm{k}}=\mathrm{Fx}_{\mathrm{k}-1}+\mathrm{G} a_{k} \\
& \text { 이때 } \quad \mathrm{F}=\left[\begin{array}{cc}
1 & \Delta t \\
0 & 1
\end{array}\right] \\
& \text { 그리고 } \\
& \mathrm{G}=\left[\begin{array}{c}
\frac{\Delta t^{2}}{2} \\
\Delta t
\end{array}\right]
\end{aligned}
$$

그 힘과 방향을 측정할 수 없는 미지의 가속도 성분 $\mathrm{G} a_{k}$ 는 Kalman 필터에서 process noise로 볼 수 있으며, 그 공
분산 행렬(covariance matrix) $\mathrm{Q}$ 는 다음과 같이 계산할 수 있다.

$$
\mathrm{Q}=\operatorname{cov}\left(\mathrm{G} a_{k}\right)=\mathrm{E}\left[\left(\mathrm{G} a_{k}\right)\left(\mathrm{G} a_{k}\right)^{\mathrm{T}}\right]=\mathrm{GE}\left[a_{k}^{2}\right] \mathrm{G}^{\mathrm{T}}=\sigma_{\mathrm{a}}^{2} \mathrm{GG}^{\mathrm{T}}
$$

측정 노이즈(measurement noise)를 $\mathrm{v}_{\mathrm{k}}$ 라고 할 때, 매 timestep마다 센서로부터 얻어지는 카메라 포즈 측정값 $z_{k}$ 는 다음과 같이 주어진다.

$$
\mathrm{z}_{k}=\mathrm{Hx}_{k}+\mathrm{v}_{k}
$$

$\mathrm{H}$ 는 실제 state 공간을 측정값 공간으로 변환해주는 행렬 로서, 이 경우 카메라 포즈만 측정되고 속도는 측정되지 않 으므로 단순히 $\mathrm{H}=\left[\begin{array}{ll}1 & 0\end{array}\right]$ 이다. 측정 노이즈도 zero mean과 표준편차 $\sigma_{z}$ 의 정규분포를 가진다고 가정한다. 이때 covariance matrix $\mathrm{R}$ 은 다음과 같이 주어진다.

$$
\mathrm{R}=\mathrm{E}\left[\mathrm{v}_{k} \mathrm{v}_{k}^{T}\right]=\left[\sigma_{z}^{2}\right]
$$

식 (5) 식 (9)를 일반적인 Kalman 필터 프레임워크에 대입하면 노이즈가 적절하게 필터링된 결과를 얻을 수 있다.

\section{IV. 그래픽 렌더링}

3장에서 보정된 카메라 데이터를 최종적으로 렌더링이 가능한 3 차원 저작 소프트웨어에 불러들이기 위하여, Autodesk Maya $^{[15]}$ 용 플러그인을 개발하였다. 플러그인은 파일로 저장된 카메라 데이터를 Maya의 그래픽 카메라 애 니메이션에 적용한다. 플러그인에서 불러들이는 데이터 파

표 1. 카메라 데이터 파일 포맷

Table 1. Camera data file format

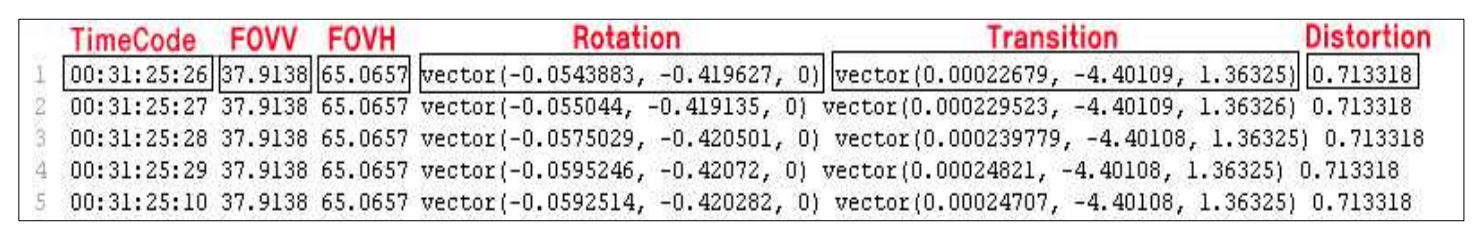



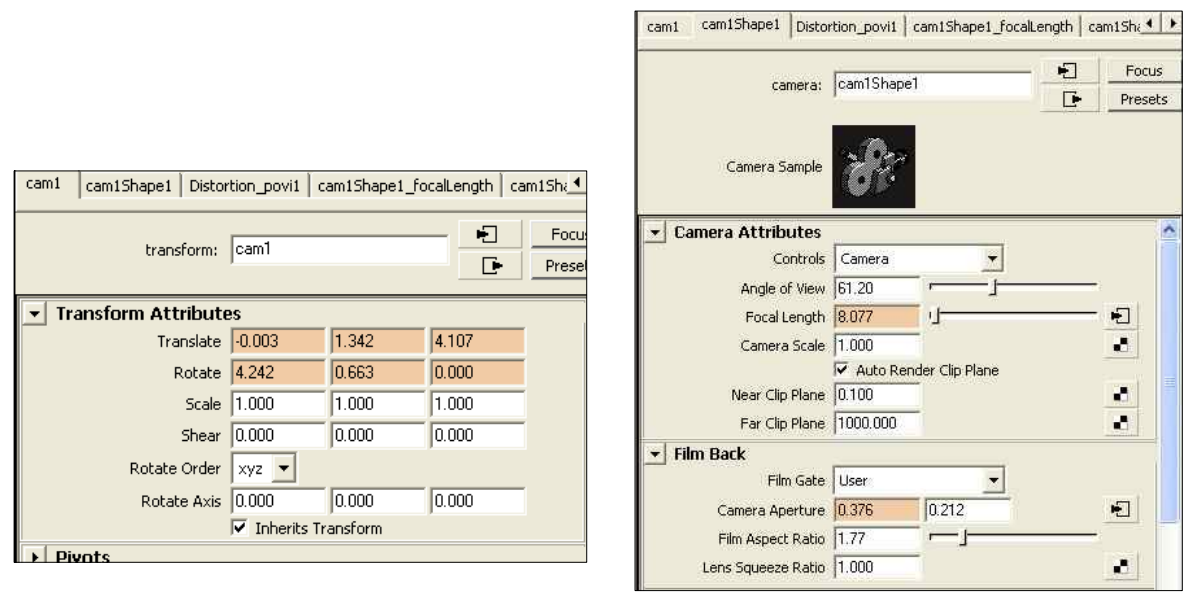

그림 4. Maya 플러그인. 카메라의 이동과 회전(왼쪽), 초점거리(오른쪽)

Fig. 4. Maya plug-in. Translation and rotation of the camera(left), focal length(right)

일은 2 장에서 설명된 캘리브레이션에 의해 표 1 과 같이 의 미 있는 카메라 데이터로 변환된 상태이다.

그림 4는 개발된 Maya 플러그인을 이용하여 카메라 데 이터를 불러들인 모습이다. 카메라 비디오는 VCR로부터 캡쳐(ingest) 과정을 거쳐 Maya에 불러들여진 상태이다. 그 림에서 그래픽 카메라의 이동과 회전, 그리고 초점거리 등 은 키프레임 애니메이션을 의미하는 오렌지색으로 표시되 어 POVIS에서 저장한 카메라 데이터가 적용되었음을 알 수 있다.

정확한 합성을 위해서는 2장의 렌즈 캘리브레이션 과정 을 통해 알아낸 렌즈 왜곡계수 $\left(\kappa_{1}\right)$ 를 그래픽 렌더링에 반 영해야 하는데, Maya의 카메라에는 렌즈 왜곡 항목이 없으 므로 Mental Ray 렌더러 ${ }^{[15]}$ 를 위한 셰이더(shader)를 작성 하였다. $\mathrm{x}_{\mathrm{u}}$ 와 $\mathrm{x}_{\mathrm{d}}$ 는 왜곡 전과 후의 이미지 좌표, $r$ 은 $\mathrm{x}_{\mathrm{u}}$ 에 서 왜곡 중심까지의 거리라고 할 때, (4)에 의해 다음의 관 계가 성립한다.

$$
\mathbf{x}_{\mathrm{d}}=\mathbf{x}_{\mathrm{u}}\left(1+\kappa_{1} r^{2}\right)
$$

이때, 화질에 손상을 주지 않기 위해 역방향 매핑 (backward mapping)을 사용하게 되므로 (10)의 역변환이 필요하나, $\mathrm{r}$ 이 $\mathrm{x}_{\mathrm{u}}$ 의 함수이기 때문에 이를 해석적으로 구하 는 것은 매우 어려운 일이다 ${ }^{[16]}$. 따라서 본 논문에서는 $\mathrm{x}_{\mathrm{d}}$ 가
주어졌을 때 반복법(iteration)에 의해 역변환된 $\mathrm{x}_{\mathrm{u}}$ 를 구하 며, 3 4 번의 반복으로 충분히 수렴하는 것을 확인하였다. 그림 5는 Mental Ray 플러그인에 왜곡계수 데이터가 적용 된 모습이다.

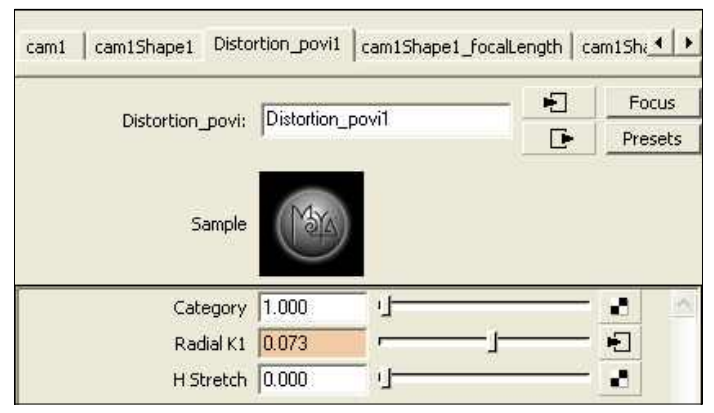

그림 5. Mental Ray 플러그인

Fig. 5. Mental Ray plug-in

\section{V. 실험 결과}

카메라 렌즈의 줌과 포커스 가동 범위를 $0 \sim 1$ 의 값으로 정규화했을 때, 줌과 포커스 모두 $0 \sim 0.5$ 의 영역에 대해 캘 리브레이션을 수행하였다. 영상에서 주점은 $1920 \times 1080$ 크 기의 이미지에서 $(957.0,538.8)$ 의 값을 얻었다. 패턴 포인 트들의 평균 재투영 에러는 1.29 픽셀로 나타났으며, 별도 의 하드웨어 장치나 3 차원 캘리브레이션 객체를 사용하지 
않고도 충분히 정확한 캘리브레이션 결과를 얻었음을 알 수 있다. 캘리브레이션 대상인 줌-포커스 영역의 외부를 사 용하거나, 알고리듬에 의한 캘리브레이션 결과가 만족스럽 지 않은 경우에는 수동으로 그래프를 보정하여 사용할 수 있다. 그림 6은 제안된 방법으로 구한 카메라 프로젝션 중 심의 이동이다. 그림 7은 줌-포커스 영역에 대한 초점거리 와 왜곡계수이다.

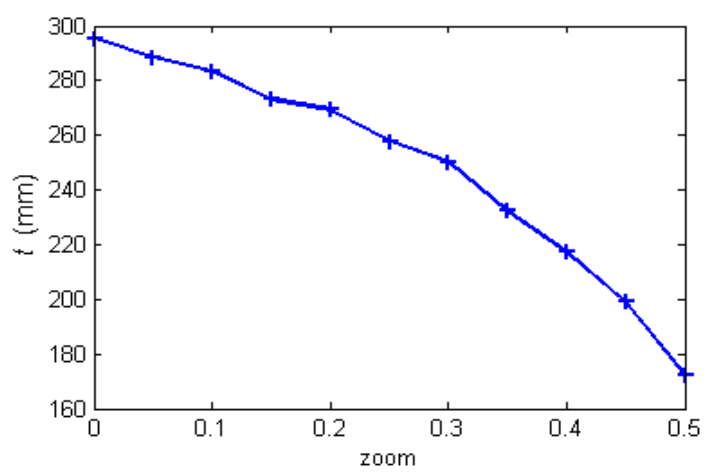

그림 6. 프로젝션 중심의 이동

Fig. 6. Translation of the projection center
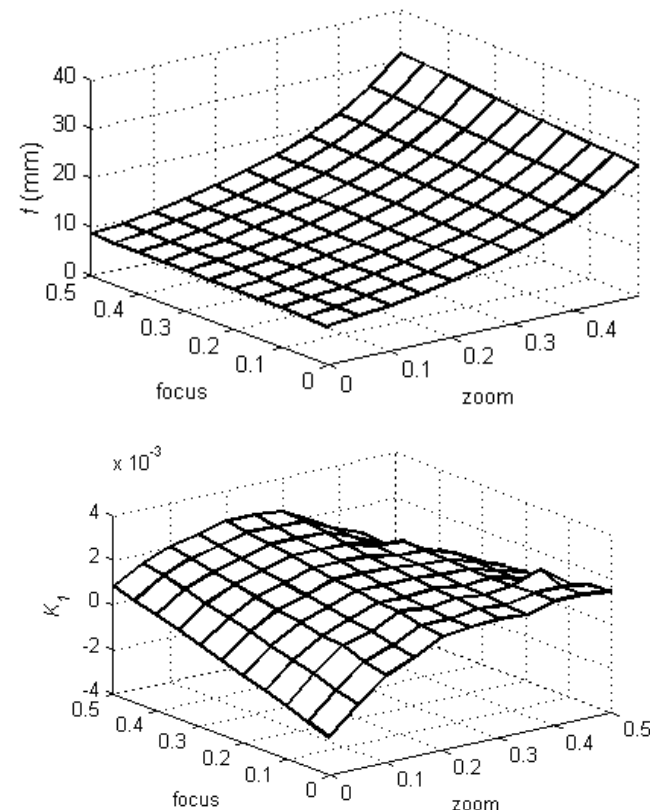

그림 7. 줌-포커스에 따른 초점거리(위)와 왜곡계수(아래)의 변화

Fig. 7. Variations of the focal length and the distortion coefficient with respect to zoom and focus
그림 8은 왜곡계수를 포함한 캘리브레이션의 정확성을 알아보기 위한 실험이다. 캘리브레이션 후 빨간 색의 패턴 코너들이 정확한 위치에 표시되며, 초록색의 참조점들 또 한 실제 구조물(벽면) 이미지 위에 정확히 겹쳐지는 것을 알 수 있다. 구조물의 위치는 줄자 등으로 측정한 다음 수동 으로 조정하였다.

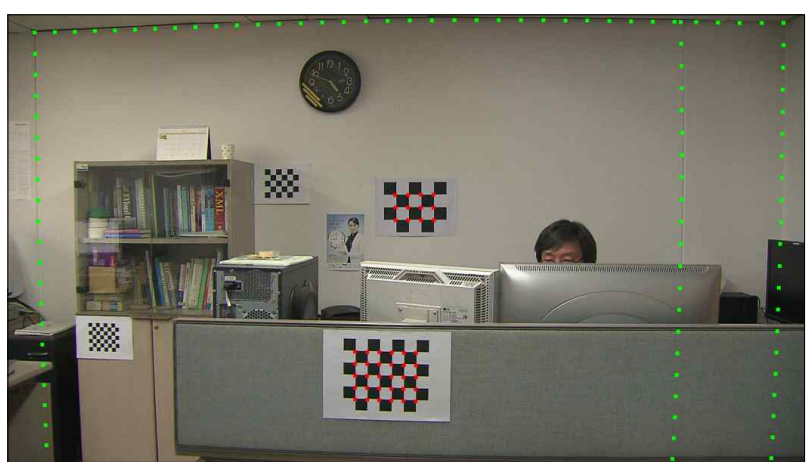

그림 8. 캘리브레이션의 정확성 검증

Fig. 8. Verification of the calibration's accuracy

그림 9는 3장에서 제안된 방법을 떨림이 발생한 카메라 의 $\mathrm{y}$ 축 회전(틸트) 데이터에 적용한 결과이다. 센서의 기계 적 부정합에 의한 데이터의 떨림이 현저하게 감소하였음을 알 수 있다.

제안된 시스템을 다큐멘터리 '누들로드' 제작에 사용하 고 결과를 분석하였다. 촬영을 위해서 Ikegami의 $\mathrm{HDL} 40$ 카메라와 Fujinon의 HA18x7.6 표준렌즈 및 HA13x4.5 광 각렌즈, 그리고 Shotoku의 리모트 컨트롤 가능한 크레인이 사용되었다.

그림 10에서 알 수 있듯이 전경과 배경의 분리(segmentation)를 위해 움직이는 사람과 소품 이외의 배경은 모두 파란 색인 블루스크린 환경에서 촬영하였다. 촬영된 영상 에는 추적 가능한 특징점이 거의 없기 때문에, Boujou 등 상용 소프트웨어로 카메라 추적을 시도하였으나 에러 메시 지를 내고 추적에 실패하였다. 상용 소프트웨어에 일반적 으로 사용되는 알고리듬에서는 부정확한 특징점 추적 등으 로 인해 DIAC(dual image of absolute conic)이 양의 정부 호(positive definite)가 되어야 한다는 조건을 충족하지 못 하면 Cholesky decomposition 등으로 이어지는 계산을 더 

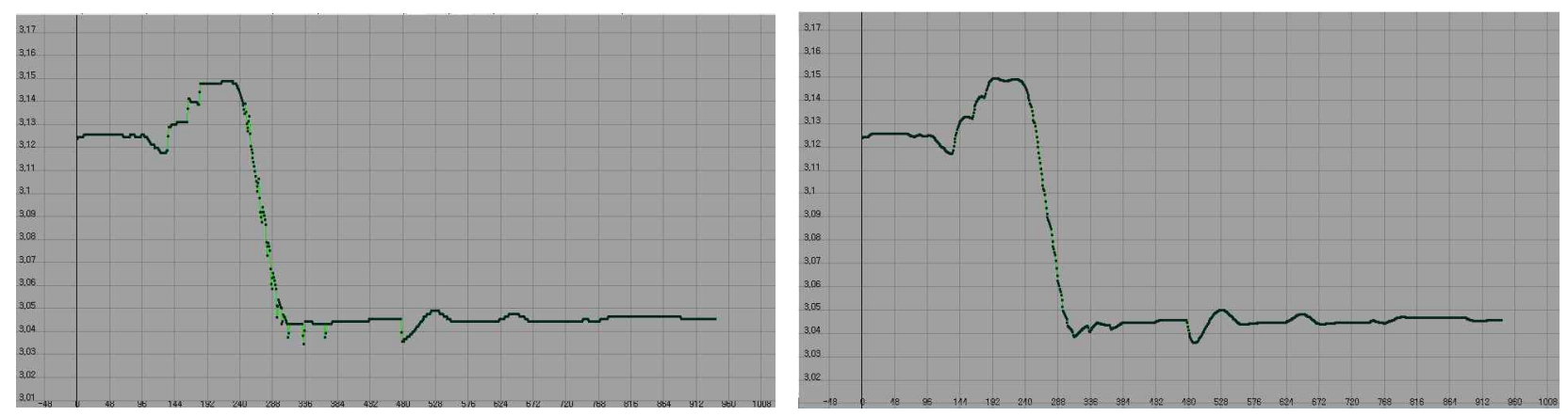

그림 9. 필터링 전(왼쪽)과 후(오른쪽)의 센서 데이터

Fig. 9. Sensor data before(top) and after(bottom) filtering

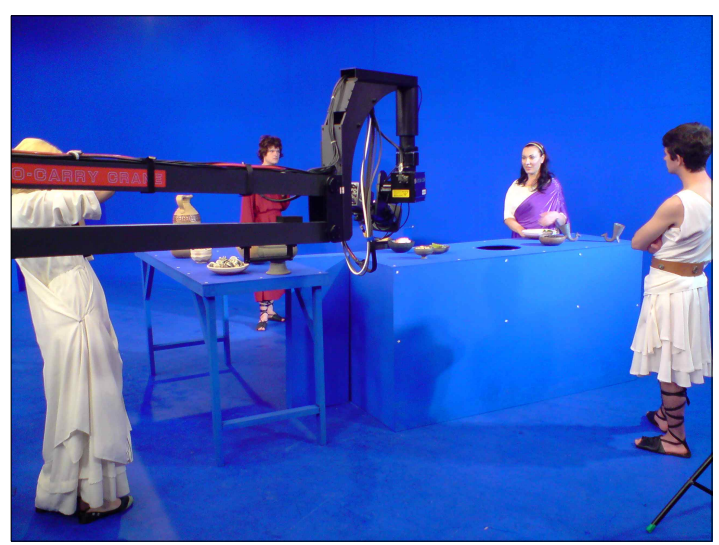

그림 10. 다큐멘터리 "누들로드" 촬영 환경

Fig. 10. Shooting environment for the documentary program "Noodle Road"
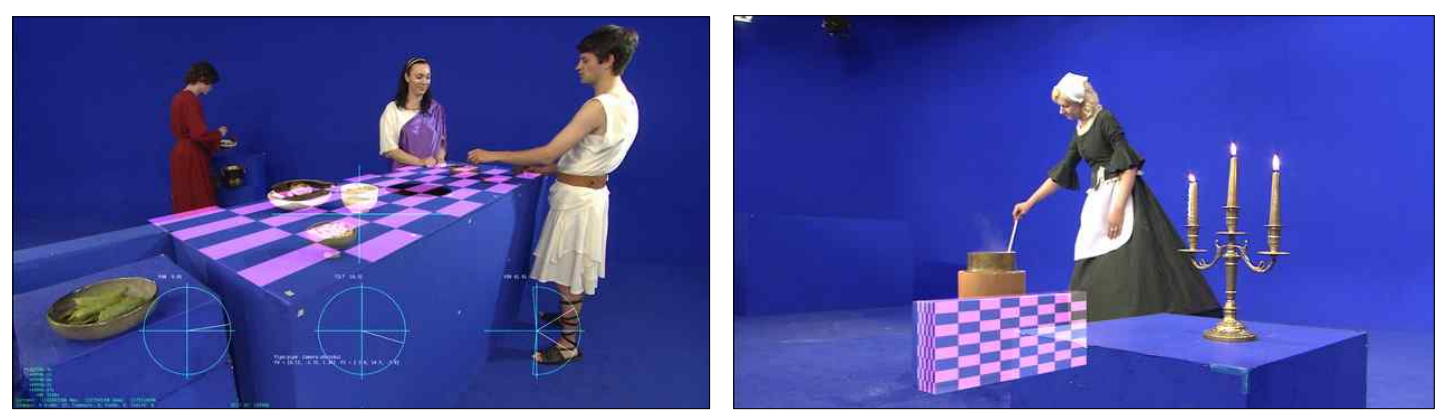

그림 11. 가상스튜디오를 이용한 미리 보기

Fig. 11. Pre-visualization with a virtual studio

이상 진행할 수 없어 추적에 실패하게 된다 ${ }^{[12,17]}$.

그림 11 은 저장된 카메라 데이터를 실시간 가상스튜디오 프로그램인 Brainstorm eStudio ${ }^{[18]}$ 에 적용하고, 영상에 테
스트 그래픽을 합성한 모습이다. 이 미리보기(pre-visualization) 과정은 카메라 데이터의 정확성을 확인하고 그래 픽 객체들을 정확한 자리에 위치시키기 위한 작업이다. 저 
장된 센서 데이터를 POVIS 소프트웨어에서 실시간으로 재 생하는 기능을 개발함으로써 가상스튜디오 프로그램에서 는 마치 실시간 카메라 추적 시스템이 연결된 것과 같은 효과를 얻을 수 있다. 그림 12는 제안된 POVIS를 이용하여 그래픽을 합성한 최종 결과이다. 카메라의 움직임에도 불 구하고 그래픽이 정확하게 합성된 결과를 볼 수 있다.
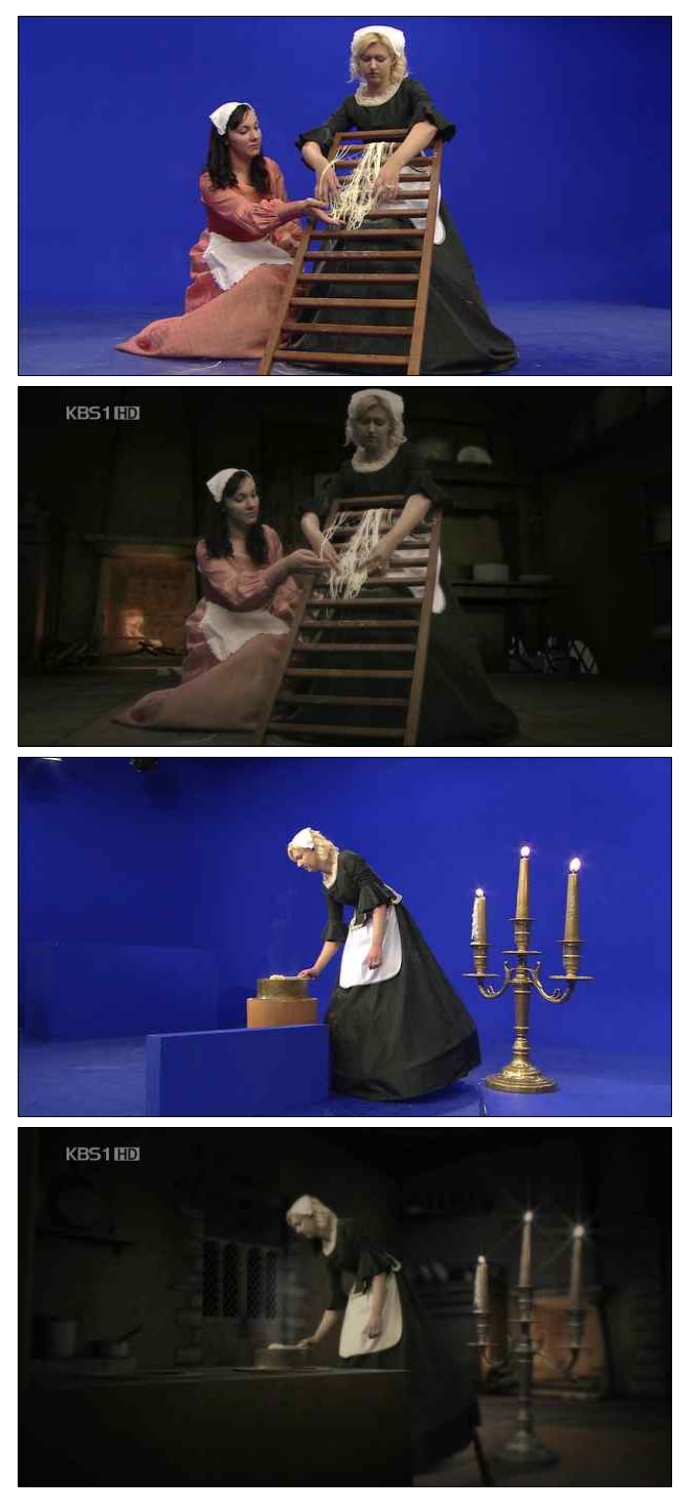

그림 12. 최종 결과. 원본 영상(1,3행), 합성 영상(2,4행)

Fig. 12. The final results. Source video(first and third row) and composited video(second and fourth row)

\section{VI. 결론}

본 논문에서는 사극과 다큐멘터리 등의 제작에 있어서 안정적인 카메라 추적과 동시에 고품질의 그래픽 렌더링이 가능한 방법을 제안하였다. 제안된 방법은 실시간 가상스 튜디오에 사용되는 카메라 센서 데이터를 저장하여 후반 제작에 사용할 수 있게 하는 시스템(POVIS)이다. POVIS 는 크게 줌렌즈 캘리브레이션, 센서 데이터 필터링, 그래픽 소프트웨어를 위한 플러그인의 세 부분으로 구성된다. 카 메라 센서에서 주어지는 모터의 회전 값을 의미 있는 카메 라 데이터로 변환할 수 있도록 줌렌즈 캘리브레이션을 수 행하였다. 또한 카메라 센서 데이터에서 발생할 수 있는 기 계적 떨림을 Kalman 필터에 의해 제거하는 방법을 제안하 였다. 이와 같이 제안된 방법들을 이용하여 정확하게 추정 된 카메라 데이터를 그래픽 소프트웨어에 불러들여 가상 카메라 애니메이션에 적용할 수 있도록 플러그인을 개발하 였다. 본 논문에서 제안된 POVIS는 실제 다큐멘터리 프로 그램 제작에 사용되어 작업 시간을 크게 단축할 수 있었다. 블루 스크린 환경에서 촬영된 영상이 주어졌을 때 상용 소 프트웨어에서는 특징점의 부족으로 카메라 추적에 실패한 반면, POVIS는 영상과 무관하게 정확한 카메라 추적 및 그 래픽 합성 결과를 얻을 수 있었다. 향후 줌렌즈 캘리브레이 션의 정확성을 더 높이고, 소프트웨어 기반 카메라 추적 방 식과의 결합을 통해 편의성을 증대시키고 사용 범위를 넓 히는 연구를 수행할 계획이다.

\section{참 고 문 헌}

[1] S. Gibbs, C. Arapis, C. Breiteneder, V. Lalioti, S. Mostafawy, and J. Speier, "Virtual studios: An overview," IEEE Multimedia, 5(1), pp.18-35, 1998.

[2] 남승진, 오주현, 박성춘, "센서기반 실시간 가상이미징 시스템의 구현," 방송공학회 논문지 8권 1호, pp.63-71, 2003년 3월.

[3] http://www.2d3.com/.

[4] http://www.thepixelfarm.co.uk/.

[5] SMPTE 12M-1-2008 Television Time and Control Code.

[6] Y. Chen, S. Shih, Y. Hung, and C. Fuh, "Simple and efficient method of calibrating a motorized zoom lens," Image and Vision Computing, pp.1099-1110, 2001.

[7] Z. Zhang, "A flexible new technique for camera calibration," IEEE 
Trans. on Pattern Analysis and Machine Intelligence, pp.1330-1334, 2000.

[8] J. Oh, S. Nam, and K. Sohn, "Practical camera calibration for augmented reality," Intl. Conf. on Computer Vision Systems, pp.225-234, 2009.

[9] M. Lourakis, "levmar: Levenberg-Marquardt nonlinear least squares algorithms in $\mathrm{C} / \mathrm{C}++, "$ http://www.ics.forth.gr/ lourakis/levmar/, 2004.

[10] M. Li and J-M. Lavest, "Some aspects of zoom lens calibration," IEEE Trans. on Pattern Analysis and Machine Intelligence, 18(11), 1996.

[11] 김대현, 신형철, 오주현, 남승진, 손광훈, “비선형 줌-렌즈 왜곡모델을 이용한 비디오 영상에서의 줌-렌즈 왜곡 보정”, 방송공학희 논문지 14 권 3호, pp.299-310, 2009년 5월.
[12] R. Hartley and A. Zisserman, Multiple View Geometry in Computer Vision, Cambridge Univ Press, 2003.

[13] E. Hemayed, "A survey of camera self-calibration," IEEE Conf. on Advanced Video and Signal based Surveillance, 2003.

[14] G. Welch and G. Bishop, "An introduction to Kalman filter," UNC-Chapel Hill, TR 95-041, April 5, 2004.

[15] http://www.autodesk.com/.

[16] L. Ma, Y. Q. Chen, and K. L. Moore, "Analytical piecewise radial distortion model for precision camera calibration," Vision, Image and Signal Processing, IEE Proceedings, 153(4), pp.468-474. 2006.

[17] H. Li and C. Shen, "An LMI approach for reliable self-calibration," IEEE Int. Conf. on Video and Signal Based Surveillance, 2006.

[18] http://www.brainstorm.es/pages/estudio.html.

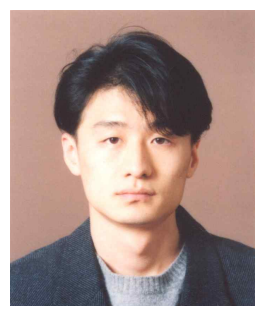

\section{오 주 현}

- 1997년 : 부산대학교 전자공학과 학사

- 1999년 : 부산대학교 전자공학과 석사

- 1999년 현재 : KBS 방송기술연구소

- 주관심분야 : 컴퓨터 비전, 증강현실, 멀티미디어

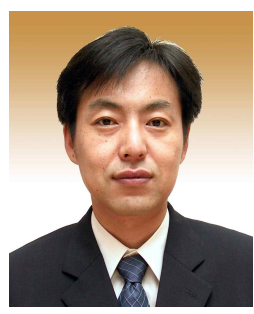

\section{남 승 진}

- 1989년 : 연세대학교 전자공학과 학사

- 1989년 : 연세대학교 전자공학과 석사

- 1991년 현재 : KBS 방송기술연구소

- 주관심분야 : 가상현실

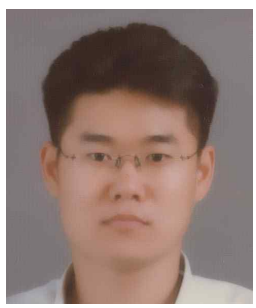

\section{전 성 규}

- 1998년 : KAIST 전산학과 학사

- 2001년 : KAIST 전산학과 석사

- 2001년 현재 : KBS 방송기술연구소

- 주관심분야 : 컴퓨터 그래픽스, 가상현실, 멀티미디어 


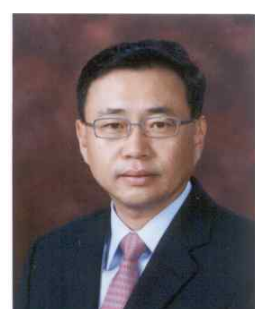

\section{손 광 훈}

- 1983년 : 연세대학교 전자공학과 공학사

- 1985년 : University of Minnesota, MSSE

- 1991년 : North Carolina State University, Ph.D.

- 1992년 1993년 : 한국전자통신연구원 선임연구원

- 1994년 : Georgetown University, Post Doctoral Fellow

- 1995년 현재 : 연세대학교 전기전자공학부 교수

- 2002년 9월 2003년 8월 : Nanyang Technological University, Visiting Professor

- 주관심분야 : 3 차원 영상처리, 영상통신 